\title{
DEGUSTACIÓN SEMIÓTICA DE UN PULIQUE CULTURAL: EL DISCURSO CULINARIO EN HOMBRES DE MAÍZ
}

\author{
Carlos Manuel Villalobos Villalobos
}

\section{(c) $($ () $\odot$}

Esta obra está bajo una licencia Creative Commons

Reconocimiento-No Comercial-Sin Obra Derivada 



\title{
DEGUSTACIÓN SEMIÓTICA DE UN PULIQUE CULTURAL: EL DISCURSO CULINARIO EN HOMBRES DE MAÍZZ
}

\author{
SEMIOTIC SAMPLING OF A CULTURAL "PULIQUE": THE \\ CULINARY DISCOURSE IN HOMBRES DE MAÍZ
}

Carlos Manuel Villalobos Villalobos

\begin{abstract}
RESUMEN
Este artículo estudia el discurso culinario en la novela Hombres de Maíz de Miguel Ángel Asturias. Considera el sistema de la alimentación como un espacio semiótico que permite leer la historia y la cultura. Los rituales alimentarios son centrales en el texto, sobre todo en lo que concierne al maíz, la planta sagrada del mito fundacional. Se estudian los elementos que conforman los platos comunales y las metáforas que relacionan a las personas con alimentos. Para explicar estas metáforas se recurre al modelo triádico de Lévi-Strauss, quien considera lo crudo, lo cocido y lo podrido como etapas culinarias asociadas a diferentes estadios de las culturas. Se concluye que no existe dicotomía entre civilización o barbarie, sino un proceso de hibridación cultural, evidente en la mezcla de ingredientes y la variedad de platos que se sirven en esta semiosis literaria.

Palabras clave: novela guatemalteca, comida guatemalteca, discurso culinario, Hombres de maíz, Asturias-Miguel Ángel.
\end{abstract}

\begin{abstract}
This article considers the culinary discourse in the novel Hombres de Maíz by Miguel Angel Asturias. The food system is as a semiotic space where is possible to read the history and culture. The rituals of culinary consumption are central in the text, especially in relation with the corn, the sacred plant of the foundation myth. We analyses the elements of communal dishes and the metaphors that relates people with the food. To explain these metaphors it is considered the triadic model of Lévi-Strauss, who considers the raw, the cooked and the rotten, as culinary steps associated with different stages of culture. In this case, we conclude that there is no dichotomy between civilization and barbarism, but a process of cultural hybridization, very evident in the mix of ingredients and dishes served in this literary semiotic process.
\end{abstract}

Key words: Guatemalan novel, Guatemalan food, culinary discourse, Hombres de maíz, AsturiasMiguel Ángel.

Dr. Carlos Manuel Villalobos Villalobos. Universidad de Costa Rica. Profesor catedrático. Director de la Escuela de Filología y Lingüística. Costa Rica.

Correo electrónico: carlos.villalobos@ucr.ac.cr

Recepción: 20- 10- 2014

Aceptación: 14- 11- 2014 


\section{La preparación semiótica del pulique cultural}

Así como Claude Lévi-Strauss viaja el interior de las comunidades autóctonas de América Latina y escribe el aclamado libro Tristes tropiques (1955), uno de los textos fundacionales de la etnología moderna, varios años antes Miguel Ángel Asturias, como escritor literario también había descrito de manera magistral el ser de las comunidades autóctonas de su país Guatemala. Esto fue posible, en parte, gracias a su estadía en la comunidad de Salamá en Baja Verapaz a donde llega con su familia en el año 1903, siendo aún un niño. A estas vivencias se agregan el estudio de la cosmogonía del Popol Vuh, así como la investigación de relatos legendarios guatemaltecos que le permiten publicar el libro Leyendas de Guatemala (1930).

Sin duda, la obra que mejor retrata la vida cotidiana y la cosmogonía de los indígenas de Guatemala es Hombre de Maíz (1949), la novela que según Gerald Martín es posiblemente la "más difícil, original, y ambiciosa publicada por un escritor latinoamericano" (Asturias, 1992, p. 508). Por su parte, Dante Liano afirma que este texto ofrece "lecturas infinitas, como ocurre con los clásicos" (Asturias, 1992, p. 541). En efecto, el texto ha sido leído de múltiples maneras, pero principalmente como un discurso "de apariencia maya" (Lienhard, 1992, p. 571) en el que es posible detectar las huellas mítico-simbólicas de los pueblos mayas y, especialmente, del Popol Vuh, el célebre libro de la cosmogénesis y mitología maya-quiché (Balzer, 2001, p. 245).

No es extraño, por lo tanto, que el artículo con el que abre la Revista de Filología y Lingüística de la Universidad de Costa Rica en 1975 sea, precisamente, un trabajo dedicado a esta novela del premio Nóbel de Literatura. Se trata de un acercamiento desde la perspectiva del estructuralismo inmanentista titulado: "Hombres de Maíz, trascendentalización de la existencia", escrito por la profesora Virginia Sandoval de Fonseca. La lectura de la profesora Sandoval de Fonseca respondía a una perspectiva académica que buscaba enfrentar el texto literario con base en los modelos estructuralistas del momento y es, en este sentido, valiosa pues da cuenta de la dicotomía que se establece entre la visión sagrada de los mayas y la perspectiva secular de los maiceros. Además, detalla las secuencias del relato y las categorías actanciales que intervienen en la historia.

Como gesto de conmemoración de este trabajo fundacional de la Revista de Filología y Lingüística, me propongo desarrollar acá algunos apuntes para una nueva lectura de este polisémico texto narrativo de Miguel Ángel Asturias.

Me interesa en este caso abordar los códigos culinarios desde la semiótica cultural. Recordemos que esta perspectiva de análisis integra las concepciones de cultura de teóricos especialistas tales como Yuri Lotman y Julia Kristeva, quienes coinciden en el concepto de texto como un espacio de producción cultural dinámica, donde historia y cultura funcionan como intertextos de amplias posibilidades semióticas (Kristeva, 1974; Lotman, 1979). De acuerdo con este enfoque, la cultura conserva información en diferentes soportes materiales y los transmite de manera colectiva. Estos procesos de memoria, comunicación y creación dejan huella en todas las prácticas sociales; ya sean artísticas, rituales, mitológicas, políticas o religiosas; igualmente, estas marcas culturales se pueden rastrear en los códigos de vestimenta, culinarios u otros de la vida cotidiana. Este enfoque de análisis concuerda con otras concepciones de cultura que también a finales del siglo XX esbozó la antropología. Uno de los estudiosos más reconocidos es Clifford Geertz, quien desde la antropología simbólica, consideraba la cultura como "un sistema de interacción de signos interpretables" (Geertz, 1992, p. 27).

En América Latina es especialmente útil el aporte del escritor Alejo Carpentier quien ofrece una definición estratégica que vincula el contexto colectivo con el devenir histórico. 
Define cultura como "el acopio de conocimientos que permiten a un hombre establecer relaciones, por encima del tiempo y del espacio, entre dos realidades semejantes o análogas, explicando una en función de sus similitudes con otra que puede haberse producido muchos siglos atrás" (Carpentier, 2004, p. 58). Igualmente es de mucha utilidad el concepto de culturas híbridas que, a propósito del los estudios culturales, propuso Néstor García Canclini (1990), pues considera que en la realidad histórica latinoamericana hay tradiciones que conviven con las ajenas y generan tramas de dislocamientos y desviaciones en continuo movimiento.

Estas concepciones de cultura aplican para comprender los referentes de la novela Hombres de Maíz, pues el relato accede no solo a la cosmogonía maya, sino a la esfera cotidiana de un grupo social que sobrevive entre los imaginarios de la tradición y las fuerzas de dislocamiento cultural. La novela hace referencia a los códigos de vestimenta, alimentación y otras prácticas cotidianas que mezclan códigos propios y ajenos, de modo que es posible explicar el fenómeno mediante el concepto de proceso de hibridación. Parto entonces de la premisa de que los códigos culinarios y, en general, los de la ingesta cotidiana son importantes marcadores de identidad cultural y espacios estratégicos para el procedimiento de interpretación semiótica. Detrás de la comida hay subtextos étnicos, económicos, históricos y de género, que sustentan una cosmovisión y determinadas perspectivas ideológicas.

\section{Los seres de nixtamal y los rituales del maíz}

El título de la novela, Hombres de maíz nos sirve en la mesa del sentido una clave estratégica para comprender lo culinario y la conexión cosmogónica. De acuerdo con el Popol Vuh el hombre está hecho de maíz, esta es la sustancia sagrada del mito fundacional. Esta conexión arquetípica pone en juego la dualidad hombre/vegetal, pues el ser humano es cosecha de maíz y el maíz, a la vez, se asume como correlato humano. Esto mismo explica que los guerreros de Gaspar Ilóm, el héroe central de la novela, peleen contra los maiceros invasores que se dedican, de manera irrespetuosa, a comercialización del maíz. El producto que siembran estos maiceros "empobrece la tierra y no enriquece a ninguno. Ni al patrón ni al mediero. Sembrado para comer es sagrado sustento del hombre que fue hecho de maíz. Sembrado por negocio es hambre del hombre que fue hecho de maíz" (Asturias, 1992, p. 9). A esto se agrega la consideración de que la tierra es un vientre materno y el modo de cultivar que utilizan los sembradores foráneos deja inútil el terreno.

El maíz es el principal alimento de los indígenas; por lo tanto, la composición material del hombre es mazorca y nixtamal (maíz crudo o cocinado). En la cosmogonía de este pueblo de Ilóm las conexiones del hombre con el mundo vegetal y animal son parte de la cotidianidad. Esta vinculación va más allá de un ligamen meramente metafórico o metonímico. No se trata de una similitud: es una sola identidad, una condición ontológica que se manifiesta al mismo tiempo en los dos ámbitos: en el de lo humano y en el de lo vegetal. Por esta razón, vender el maíz es como vender la carne humana. No tiene cabida en el imaginario de la comunidad la posibilidad de comerciar el grano. Este ideario está presente en las conversaciones diarias. Véase el siguiente texto donde se materializa en la cotidianidad esta idea:

\footnotetext{
[...] nosotros somos hechos de méiz, y si de lo que estamos hechos, de lo que es nuestra carne, hacemos negocio; es lo aparente lo que cambia, pero si hablamos de las sustancias, tan carne es un hijo como una milpa. La ley de antes autorizaba al padre a comerse al hijo, en caso de estar sitiados, pero nunca llegó a autorizarlo a matarlo para vender la carne. Dentro de las cosas oscuras entra el que podamos alimentarnos de méiz, que es carne de nuestra carne, de las mazorcas, que son como nuestros hijos; pero todo acabará pobre y quemado por el sol, por el aire, por las rozas, si se sigue sembrando méiz para negociar con él, como si no fuera sagrado, altamente sagrado. (Asturias, 1992, p. 180)
} 
Este mito fundacional maya es el principal marcador de identidad en el pueblo de Ilóm. El acto de sembrar el maíz para cambiarlo por dinero es codicioso y alcanza una condición que podría incluso asociarse con lo pecaminoso. Se trata de una profanación inaceptable desde la mirada que defiende la naturaleza sagrada de este grano. Dañar la planta del maíz, por lo tanto, equivale al mismo acto de invocar la muerte: "La mano del que violentamente quiebra la mata de maíz, para que la mazorca acabe de sazonar, es como la mano que parte en dos el sonido de la campana, para que madure el muerto" (Asturias, 1992, p. 41). El maíz es sangre de la misma sangre humana. Es tal el arraigo de este mito que su defensa es el fundamento del conflicto bélico de graves consecuencias que se narra en la novela. Los hombres de Ilóm defienden con vehemencia este ideario y pagan con la muerte.

La importancia del maíz explica también la cantidad de términos alusivos a partes de la planta o a su cultivo. Maíz es méiz y la jerga popular. Otros términos citados son milpa; tapizcar (palabra de origen náhuatl que significa cosechar el maíz); mazorca; shilote, chilote o jilote (mazorca de maíz tierno); elote; olote (corazón de la mazorca); tuza (hoja de la mazorca) y tazol (hoja seca de la mazorca).

En cuanto a los productos derivados del maíz la variedad culinaria es también sumamente amplia. Entre los mencionados en la novela están: la tortilla, el pixtón (tortilla gruesa), el totoposte (tortilla fría y dulce que comen los soldados) el tamal y el pozol. El nixtamal es el maíz cocido. Del maíz también se preparan distintas bebidas tales como el chilate (atol de maíz con chile o cacao), atol, atol shuco, eloatol (atol de maíz tierno) y el pinol. A estos preparados líquidos hay que agregar el aguachigüe, agua chiva o agua chigua, que es el agua que se le agrega a la masa en la preparación de las tortillas. Los residuos de masa que quedan en este líquido se llaman chingaste y se utiliza como bebida para los animales domésticos.

Si bien, la tortilla es el derivado cotidiano más utilizado, el tamal es el producto con más variantes. Hay tamales de distintos tamaños y los hay en color rojo y negro: "los rojos salados, los negros de chumpipe, dulces y con almendras; y tamalitos acólitos en roquetes de tuza blanca, de bledos, choreques, lorocos, pitos o flor de ayote; y tamalitos con anís, y tamalitos de elote, como carne de muchachito de maíz sin endurecer" (Asturias, 1992, p. 20). Además, "Las mujeres comían unas como manzanarrosas de masa de maíz raleada con leche, tamalitos coloreados con grana y adornados con olor" (Asturias, 1992, p. 20).

De acuerdo con Julián López-García, quien ha estudiado el tema de la comida indígena guatemalteca, el tamal es una de las comidas festivas más recurrentes en la comunidad MayaCh'orti', el grupo que estudia. Pero es muy probable que esto aplique también para las demás comunidades, pues el maíz y este ideario no se restringen a un grupo específico. De acuerdo con las investigaciones de López-García: "no existe velación, ni kikín, ni velatorio que no se precie si no hay tamales que ofrecer. Después de cocer un tamal y entregarlo suele abrirse con parsimonia e invitar a que se huela el aroma humeante que despide" (2003, p. 241).

Los tamales además funcionan en Hombres de maíz como metáfora antropomorfa, pues las variables de forma y sabor corresponden a las diferencias que hay entre las personas. Hay tamales que son más apetecidos por los varones; mientras otras presentaciones, como los tamalitos coloreados con grana, están hechos más para mujeres. Igual podría decirse a propósito de la edad pues hay tamales de gran tamaño y tamalitos. Otra de las condiciones que facilitan esta analogía antropomórfica es la envoltura con que se cocina y se sirve el tamal: "Las gentes son como tamales envueltos en ropa. Se les sale lo colorado" (Asturias, 1992, p. 45). 
El tamal es en el espacio de la fiesta colectiva el plato principal. El ritual del consumo permite compartir con los demás. Es, como lo apunta el narrador de la novela, un medio para entrar en confianza con los vecinos:

\begin{abstract}
Las tamaleras, zambas de llevar fuego, sacaban los envoltorios de hoja de plátano amarrados con cibaque de los apastes aborbollantes y los abrían en un dos por tres. Las que servían los tamales abiertos, listos para comerse, sudaban como asoleadas de tanto recibir en la cara el vaho quemante de la masa de maíz cocido, del recado de vivísimo rojo y de sus carnes interiores, tropezones para los que en comenzando a comer el tamal, hasta chuparse los dedos y entrar en confianza con los vecinos, porque se come con los dedos. (Asturias, 1992, pp. 19-20)
\end{abstract}

A pesar de la interdicción del mito en cuanto a la prohibición de la venta del maíz, existe un contexto donde es posible romper la regla: la práctica de la venta callejera de tortillas. Se trata de un quehacer fundamentalmente femenino y ampliamente practicado en el interior de la comunidad. Si bien, la mazorca como tal no es objeto de intercambio, paradójicamente, una vez convertido en tortilla puede ser objeto de venta pública. De este modo, las ventas de tortillas son estampas cotidianas que se describen a lo largo de la novela. Véase, al respecto, la siguiente escena:

\begin{abstract}
Un trastorno aquel palmearse unas a otras, llamándose como se llama a las tortilleras cuando pasan por la calle, con palmaditas de mano. El sudor les raja la cara de barro sumiso. Les brillan los ojos ribeteados de colorado de ocote, por culpa del humo. Crío a la espalda, unas. Otras panzonas, esperando hijo. Las trenzas en culebrerío sobre la cabeza. Todas con los brazos alistonados y escamosos de aguachigüe. (Asturias, 1992, p. 57)
\end{abstract}

Esto es posible quizá porque no se trata de una práctica que implique relaciones capitalistas, como la vinculación patrón obrero que ocurre en el caso de la siembra comercial de maíz a mayor escala. Sin embargo, aún en estos casos persiste una imagen de degradación en quienes desarrollan esta práctica. Las vendedoras suelen ser mujeres madres de condición muy humilde que sobreviven gracias a estas ventas. Obsérvese como en todos los distintos casos se refuerza esta imagen:

Las tortilleras con el mijo en el rebozo a tuto y el canasto en la cabeza sobre el yagual, y las que no tenían mijo, con el rebozo sobre el canasto en forma de cortina que les caía de lado y lado de las orejas, para librarse de la fuerza del sol, camisa de colorines, nagua y fustanes arremangados en el refajo y desnudos y muy limpios los pies que asentaban apenas en el camino, al pasar corriendo. Goyo Yic las reconocía por el paso menudo, seguido, torteante, andaban, como haciendo tortillas de tierra, y porque de vez en cuando le daban el golpe a la respiración con silbidos de molendera que cambia el ritmo de la mano en la piedra de moler. (Asturias, 1992, p. 100)

Aquí se muestra cómo las vendedoras de tortillas viven en condiciones paupérrimas. Son madres que deben alimentar a sus hijos y es por eso que no les queda más remedio que dedicarse al negocio de las tortillas; es decir, a ejercer una especie de trabajo proscrito, como si fueran prostitutas de la calle.

En la dimensión semiótica del maíz como símbolo cultural, queda claro que la configuración del mito fundacional cohesiona la identidad del pueblo de Ilóm. Esta planta sagrada es masa y carne; es bebida y sangre. Establece lo sagrado y al mismo tiempo define los interdictos de la comunidad. Quienes desacatan la fuerza simbólica de la sacralización del maíz son los proscritos sociales.

Como hemos visto, el mito maya de la vinculación entre lo humano y el maíz implica también una fuerte conexión entre la vida y lo telúrico. Por ello, si el maicero irrespeta la tierra, acabará también irrespetándose a sí mismo. Por lo tanto, si arruina el campo de la siembra, 
inevitablemente se arruinará. Esta conexión es esencial para entender la vida. Cuando los hombres: "han sembrado y no llueve se van poniendo lisos" (Asturias, 1992, p. 37), mientras tanto las mujeres sufren el mal carácter. Pero cuando llueve retorna la alegría en todos.

La tierra es una metáfora del vientre femenino y es por lo tanto hembra. Por esto, el color de los senos son del mismo color de la tierra llovida. La tierra es una madre que amamanta:

Pesaba la chiche para dar de mamar como la tierra mojada. Sí, la tierra era un gran pezón, un enorme seno al que estaban pegados todos los peones con hambre de cosecha, de leche con de verdad sabor a leche de mujer, a lo que saben las cañas de la milpa mordiéndolas tiernitas. (Asturias, 1992, pp. 37-38)

Como puede observarse en esta cita, la tierra nutre como madre. Hasta aquí llegan por lo tanto la importancia que tiene el tema de la alimentación en las comunidades. La sobrevivencia del grupo está totalmente ligada con esta dimensión telúrica y con cultivo de maíz como alimento cotidiano, festivo y ceremonial.

\section{Los festines culinarios en la tierra de Ilóm}

Entre los modos de preparar las comidas, más allá de los productos del maíz ya descritos, la novela hace referencia a una amplia gama de variables: sancochos, caldos, guisos, asados y fritos, principalmente. Un recuento de los principales modos de cocción permite resumir los siguientes platos: el cuscún o coscún, la fritanga, el pepián o pipián (guiso típico con diferentes carnes), el pulique (guiso con chile guaque, miltomate cocido, arroz, pan molido y achiote), el sancocho y las enchiladas. A esto se agregan distintos tipos de pan tales como pan de huevo, pan dulce, pan de maxtate y pan de recado.

En cuanto a los productos que se utilizan en la elaboración de los platos se citan principalmente los siguientes: aguacate, achiote, ajo, chile, chile haque, ejote (vaina de frijol), frijol, ayote, chilacayote, güicoy o huicoy, (variedad de calabaza) guineo, güisquil o huisquil (chayote), ichintal (raíz de chayote), izote, miltomate, pacaya, papa, plátano, suquinay y yuca. Aparecen también referenciadas algunas frutas tales como caimito, coco, guanaba, guayaba, jocote, mamey, naranja agria, papaya, piñuela, pitahaya, toronjas y zapote. La caña de azúcar y el coyol son importantes en la elaboración de bebidas, especialmente las fermentadas. Además de los animales domésticos tales como la gallina, el chumpipe (pavo), el chivo y el cerdo, se incluyen en la cocina otros animales tales como el garrobo, tepezcuinte y armado. En cuanto a los peces destacan la mojarra y la sardina. También se hace alusión al chorizo, a los encurtidos y a los derivados animales tales como la leche, huevos y queso.

Para preparar este gran pulique de evidente hibridez cultural es necesario ubicar en primer lugar las condiciones de producción. Se mantiene la tradición de la cocción mediante el uso de la leña y la construcción de fogones de piedra. Sin embargo, también "se cocinaba con petróleo, aunque en algunas casas existía el poyo cristiano, de cal y canto, con hornillas, y se cocían los alimentos con leña o carbón vegetal" (Asturias, 1992, p. 245). En este espacio tiene lugar la confluencia de todo aquello que se le añade a la tradición. Este es el mejor espacio para entender la hibridación de los códigos culturales. De este modo, es posible un amplio y rico menú festivo que une a la comunidad, le crea condiciones de identidad y al mismo le permite integrar préstamos ajenos. Véase la siguiente estampa cotidiana que ocurre en el marco de una de las celebraciones comunales: 


\begin{abstract}
Adolescentes con cara de bucul sin pintar jugaban entre los ancianos, entre las mujeres, entre los hombres, entre las fogatas, entre los brujos de las luciérnagas, entre los guerreros, entre las cocineras que hundían los cucharones de jícara en las ollas de los puliques, de los sancochos, del caldo de gallina, de los pepianes, para colmar las escudillas de loza vidriada que les iban pasando y pasando y pasando y pasando los invitados, sin confundir los pedidos que les hacían, si pepián, si caldo, si pulique. Las encargadas del chile colorado rociaban con sangre de chile huaque las escudillas de caldo leonado, en el que nadaban medios güisquiles espinudos, con cáscara, carne gorda, pacayas, papas deshaciéndose, y güicoyes en forma de conchas, y manojitos de ejotes, y trozaduras de ichintal, todo con su gracia de culantro, sal, ajo y tomate. También rociaban con chile colorado las escudillas de arroz y caldo de gallina, de siete gallinas, de nueve gallinas blancas. (Asturias, 1992, p. 19)
\end{abstract}

Esta referencia muestra no solo las maneras de preparar la comida, sino la variedad de productos que se utilizan en la elaboración del recetario. Entre los aspectos culinarios más destacables está el uso del picante que será recurrente a lo largo de la novela. En cuanto al consumo de la carne igualmente las referencias son abundantes: "Las encargadas de los asados le gozaban el primer olor a la cecina: carne de res seca compuesta con naranja agria, mucha sal y mucho sol" (Asturias, 1992, p. 20).

No parece existir un límite en cuanto a las posibilidades culinarias que se describen. Todo gira alrededor de la comilona. Las opciones, las mezclas y la forma cómo los personajes consumen el banquete resulta una suerte de fiesta bacanal: "Otros ojos se comían otros platos. Güiras asadas. Yuca con queso. Rabo con salsa picante que por lo meloso del hueso parece miel de bolita. Fritangas con sudor de sietecaldos" (Asturias, 1992, p. 20). Otra de las características de los comensales es la avidez con la que engullen las bebidas, tal y como se describe en la siguientes escena: "Los bebedores de chilate acababan con el guacal en que bebían como si se lo fueran a poner de máscara, para saborear así hasta el último poquito de puzunque salobre" (Asturias, 1992, p. 20). Recordemos que el puzunque es un residuo de comida que queda en el fondo de un recipiente. La imagen de los comensales acabando todo hasta la última borona pone en escena un festín de hambrientos. No asistimos por lo tanto a un banquete con orden o etiqueta, ocurre más bien un efecto carnavalesco.

En lo que sí hay distinción es en cuanto al género sexual, pues los hombres consumen más picante y aguardiente, mientras lo dulce está reservado especialmente a las mujeres. Véase esta escena que alude a las mujeres, quienes igualmente sin ningún protocolo sacian el apetito:

La manteca caliente ensayaba burbujas de lluvia en las torteras que se iban quedando sin la gloria de los plátanos fritos, servidos enteros y con aguamiel a mujeres que además cotorreaban por probar el arroz en leche con rajitas de canela, los jocotes en dulce y los coyoles en miel. (Asturias, 1992, p. 21)

Además de los plátanos, el arroz en leche, los jocotes y los coyoles en miel, otros dulces que se describen son la cajeta, el matagusanos (pasta dulce), la melcocha, la rapadura y las rapaduritas.

En cuanto a las bebidas, además del atol, el eloatol y el pinol, ya citados, se citan el suchil (refresco de jocote), la horchata, el agua de canela, el agua de chilacayote, el chan, el café, el cacao y las bebidas fermentadas: la chicha, el guaro, el guarazo, el mataburro y el rompopo. Véase una de las descripciones que se hace en el texto sobre los rituales de la bebida: "Batido en jicaras que no se podían tener en los dedos, tan quemante era el líquido oloroso a pinol que contenían, agua con rosicler en vasos ordinarios, café en pocilio, chicha en batidor, aguardiente a guacalazos mantenían libres los gaznates" (Asturias, 1992, p. 21).

De acuerdo con Julián López-García (2003, p. 241), el pinol es una especie de café de maíz y es fundamental como acompañante de las tortillas y del frijol. Esta bebida es una de las más cotidianas también en la novela, a diferencia del atol, la chicha y el chocolate que son 
bebidas de carácter más festivo. En la novela la bebida que goza del mayor uso festivo es el chocolate, pues se utiliza para matrimonios y bautizos: "Pero era tan sabroso el chocolate de casamiento. Chocolate de bautizo. Las fiestas se celebran con chocolate y tortas de pajaritos" (Asturias, 1992, pp. 192-193).

Siguiendo el estudio que hizo López-García (2003, p. 241) de los rituales de las bebidas en una comunidad indígena guatemalteca, aparte de lo cotidiano y lo festivo, existe también una bebida ceremonial: en este caso es el chilate. Sin embargo, en el texto estudiado este uso no aparece claramente con este sentido.

Finalmente, habría que hacer alusión a la ingesta adictiva de las bebidas fermentadas, uno de los temas que aborda ampliamente la novela. Por ejemplo, en la cárcel se consume ampliamente el licor gracias al truco de hacerlo pasar por agua de coco: "El negocio de los cocos fue redondo como los cocos. Todos compraron su coco cargado. En lugar de agua de coco se llenaban las cáscaras con aguardiente, unos, y otros con ron. Los de ron eran más caros" (Asturias, 1992, p. 273).

\section{Los sancochos de la civilización y la barbarie}

Como se puede observar en estas enumeraciones culinarias hay aquí productos tradicionales que incluso mantienen el nombre en las lenguas originarias y otros importados que se incorporaron a la cocina como parte del proceso de transculturación. Es por esto que no es posible establecer una diferencia entre la tradición y la adopción cultural. Lo que hay es una mezcla que integra los distintos productos y producciones. Esta mixtura no solo ocurre en la olla, sucede también en otras esferas de la cotidianidad. En este sentido funciona como metonimia de la semiótica cultural de la comunidad.

Si nos atenemos a la tesis fundacional levistrosiana (1968) de la tríada crudo/cocido/ podrido, y sus correlatos naturaleza/cultura o elaborado/no elaborado y lo intentamos vincular con las prácticas gastronómicas del grupo social que se describe en Hombres de maíz, claramente estas dicotomías estructurales no funcionan.

Tal y como se apuntó en el apartado anterior, el recetario que se ofrece es detallado y amplio, y en la misma olla cultural aparecen mezcladas las dicotomías que el citado antropólogo francés intentaba encontrar en los relatos míticos. Aquí, cualquier díada oposicional: asado/hervido, crudo/podrido, húmedo/seco, ahumado/no ahumado, etc. resultan inmediatamente anuladas.

Es decir, si a partir de la comida, quisiéramos establecer una diferenciación entre civilización y barbarie, el modelo de Lévi-Strauss no tendría aplicación práctica y se descalifica frente a la compleja mezcla de códigos. Más bien, se trata de un cuestionamiento que se hace a la tradición antropológica europea. Al respecto Miguel Ángel Asturias mediante un guiño irónico pone a los propios personajes a reflexionar sobre el tema:

- Todo lo que se relaciona con el alimento del hombre es barbarie; yo no sé por qué dicen los hombres que han dejado de ser bárbaros; no hay alimento cevelizado.

-El maíz.

-El méiz, decís vos; pero el méiz cuesta el sacrificio de la tierra que también es humana; ya te pusiera yo a cargar un milpal en la espalda, como la pobre tierra. Y más bárbaro lo que hacen: siembra de méiz para vender [...]. (Asturias, 1992, p. 179)

Al igual que la tesis del pensador cubano José Martí, quien plantea en el ensayo "Nuestra América" que "no hay batalla entre la civilización y la barbarie, sino entre la falsa 
erudición y la naturaleza" (Martí, 1979, p. 33), en Hombres de Maíz, igualmente se invierten los códigos maniqueos de esta dicotomía. Los bárbaros son los que niegan la condición natural, en este caso los que no entienden la conexión entre el hombre y lo telúrico. La naturaleza que alimenta al hombre es el principio máximo que evidencia lo civilizado. Los que negocian con esta madre se ubican en los linderos de la barbarie.

\section{Las metáforas de lo crudo, lo cocido y lo podrido}

Así como el tamal es un ser humano vestido de hojas, abundan en Hombres de maíz las metáforas culinarias que comparan a las personas con algún tipo de alimento. Estas representaciones abarcan los posibles estados del alimento para su consumo. En la teoría clásica del estructuralismo levistrosiano, al que hicimos referencia, se plantea un triángulo esquemático que propone lo crudo como la representación originaria de la condición natural de los alimentos; lo cocinado como la transformación cultural del alimento preparado y lo podrido como una alteración de la comida en proceso de degradación, aunque igualmente puede ser susceptible de consumo. En el texto que nos ocupa, la personificación y las construcciones metafóricas se pueden sistematizar con base en esta trilogía.

El personaje que es descrito como lo primigenio natural es Gaspar Ilóm. Como coincidencia, las metáforas culinarias que lo describen lo asocian a imágenes de productos en estado crudo. Véase el siguiente ejemplo: "Vivo, alto, la cara de barro limón, el pelo de nige lustroso, los dientes de coco granudos, blancos, la camisa y calzón pegados al cuerpo, destilando mazorcas líquidas de lluvia lodosa, algas y hojas, apareció con el alba el Gaspar Ilóm" (Asturias, 1992, p. 23). En esta cita los elementos comestibles en estado crudo que se utilizan para la descripción del personaje son limón, coco, mazorcas y algas. Es el hombre de maíz en su estado puro. No en vano es el héroe romántico de la novela, el líder que muere como resultado de la invasión.

Por otra parte, las etapas de la producción del maíz sirven como comparación para establecer distintas comidas que se asocian con las edades humanas. Es en este espacio donde la metaforización se asocia específicamente con lo cocinado. Véase esta descripción cronológica que se hace de la vida de la madre de los Tecún:

\footnotetext{
La nana, madre de los Tecún, parecía salir de muchos años y trabajos. De años sucios de chilate de maíz amarillo, de años blancos de atol blanco con granos de elote, uñas de niños de maíz tiernito, de años empapados en los horrores rojos de los puliques, de años tiznados de humo de leña, de años destilando sudor y dolor de nuca, de pelo, de frente que se arruga y abolsa bajo el peso del canasto cargado en la cabeza. (Asturias, 1992, p. 85)
}

En este texto la madre de los Tecún representa un proceso culinario que va cambiando de cocción según la vida. Cada etapa es un momento diferente, un sabor y un color específico en equivalencia con diferentes presentaciones del maíz y lo culinario. Esta estapas son el chilate, el atol y el pulique.

En otros momentos los personajes pueden ser metáfora de condimento o bien representar el aceite o la manteca, como en esta descripción que se hace de una de las indígenas: "La cara negra, el pelo enmarañado y la ropa mantecosa de la mujer contrastaban con sus dientes blancos como la manteca" (Asturias, 1992, p. 32).

Este sistema metafórico llega casi a lo hiperbólico cuando los personajes, igual que el alimento, se cocinan o se asan directamente con el fuego. Es el caso de los indígenas que se corren a apagar uno de los incendios en la milpa y empiezan a quemarse: 


\begin{abstract}
La humazón borraba por ratos al señor Tomás. No se veía ni el bulto del anciano padre que busca a su hijo entre los resplandores del fuego. Como si se hubiera quemado. Pero en el mismo sitio o en otro, cercano o distante, resaltaba parado, mirando fijamente el fuego, la cara tostada por la brasa del incendio, las pestañas y el pelo canches de los chamuscones, sudando a medianoche o en las amanesqueras, igual que si le hicieran sahumerios. (Asturias, 1992, p. 35)
\end{abstract}

Dada la intrínseca conexión entre el hombre y el maíz, la quema de la milpa implica también la quema de los indígenas. Algunos incluso mueren arrasados por el fuego. También aparecen descripciones que se refieren al estado de estos hombres trasformados por el fuego culinario. Es el caso de Nicho Aquino, un anciano que tenía las "manos de color de maíz negro" (Asturias, 1992, p. 179) y que dice de sí mismo: "Te estás fijando en mis manos chamuscadas, tostadas, negras" (Asturias, 1992, p. 177). A estas imágenes del hombre cocinado y tostado se une también la metáfora del hombre asado: "el señor Nicho sentía que se asaba" (Asturias, 1992, p. 263).

Adicionalmente, en el marco del ciclo de la vida, así como el maíz es alimento del hombre; el hombre es alimento de la Tierra. Esta idea está claramente esbozada en la siguiente reflexión de uno de los personajes indígenas:

\footnotetext{
[...] los que se han entregado a sembrar méiz para hacer negocio, dejan la tierra vacía de huesos, porque son los huesos de los antepasados los que dan el alimento méiz, y entonces, la tierra reclama huesos, y los más blanditos, los de los niños, se amontonan sobre ella y bajo sus costras negras, para alimentarla. (Asturias, 1992, p. 179)
}

En este último caso, sin embargo, no se trata en el sentido estricto de una construcción metafórica. Esta es la base del mito fundacional. Hombre y maíz son alimento de un mismo proceso cíclico. Desde el punto de vista del mito no es una comparación. Aquí se trata, como ya se había acotado anteriormente, de una identificación ontológica que trasciende el efecto retórico. Sin embargo, en la novela, para reforzar esta identidad arquetípica se recurre, como hemos visto, a la metaforización.

En la última etapa de este sistema metafórico está lo podrido. Este se representa principalmente mediante las sinestesias odoríficas. El olor nauseabundo permite la asociación con lo que corresponde al estado de descomposición. Uno de los indígenas es: "clinudo, miltomatoso y hediondo a calentura, en camisa y calsonío de manta de costal de harina" (Asturias, 1992, p. 68); de uno de los personajes llamados Casimiro se dice que los ronquidos "huelen a huevo güero" (Asturias, 1992, p. 218); el administrador de Correos es descrito como "hediondo a cigarrillos apagados en salivazos" (Asturias, 1992, p. 146) y la gente que viene a la procesión del viernes de Semana Santa se distingue por la gama de olores particulares:

Los de los altos olorosos a lana, risco y chopo. Los de la costa apestando a sal y sudor marino. Los de oriente, hechos de tierra de cuestas, despidiendo huele de tabaco, queso seco, acida yuquilla y almidón en bolita. Y los del norte, olorosos a chipichipi, jaula de cenzontle y agua cocida. (Asturias, 1992, p. 101)

Lo maloliente en ocasiones se contrasta con olores agradables como por ejemplo la pintura que se hace de una pareja que llega a casarse: la novia llega con olor a toma de agua "y él hediendo a pixtón y a chivo" (Asturias, 1992, p. 29).

De este modo, como crudos, cocidos y podridos, se distribuyen las representaciones de los personajes que son servidos simbólicamente en esta mesa semiótica.

Como acotación adicional encontramos también una metáfora que se refiere a la parte emocional. Luego de la gran fiesta, de la bacanal que termina con exceso de bebidas fermentadas, queda el sinsabor: "el mal sabor de la boca, el estómago cocido por los tragos y la 
tristeza que es como la ceniza de la alegría” (Asturias, 1992, p. 232). Una vez que se ha apagado el fuego y se termina la ingesta viene el capítulo del malestar. La resaca entonces es la ceniza que queda en el fogón. La ceniza es una sensación desagradable luego del deleite que produjo el fuego. Con esta imagen el sistema metafórico de lo culinario está completo.

\section{Degustaciones pendientes}

Hasta aquí el destape de las ollas y el pulique cultural del pueblo de Ilóm. No ha sido posible sin embargo, degustar en este artículo todo lo que ofrece la novela. Es mejor así, pues siempre habrá convidados a seguir probando estos signos inacabables. Inicialmente pensé en incluir también la ingesta de productos curanderos, pues igualmente hay un sistema de gran riqueza. No solo se hace referencia a ciertas hierbas medicinales, sino incluso a productos cotidianos que se incluyen en la mesa diaria y que son curativos. Se pueden entrever en este tema códigos de interdicción y sacralización y se plantea la paradoja cultural del enfrentamiento entre la medicina tradicional y la moderna.

Igualmente, lo culinario puede ser estudiado aún con mayor detalle en los rituales cotidianos y ceremoniales. Por ejemplo, cuando los hombres están en guerra sabemos con detalle qué consumen, pues se alude especialmente al totoposte que es la tortilla fría y de la que se deriva el término "totoposteado", que se refiere a la persona quebrantada. También aquí se da una correlación metafórica entre lo que come el soldado y una posible característica psicológica de los personajes.

Otro espacio de representación culinaria es el matrimonio donde se consumen "rosarios de rapaduritas cruzados como cananas de balas dulces en los pechos mozos. Las figuritas de los güipiles hechas de bulto con azúcar de colores en las cajetas de antojos de colación. El pan de maxtate con ajonjolín" (Asturias, 1992, p. 29). Este sistema específico abre adicionalmente un capítulo posible de diferenciación simbólica entre la comida para el hombre o la mujer.

Otro capítulo que bien podría desarrollarse con más detalle es la construcción de la identidad colectiva en el marco de la fiesta religiosa, pues la comida tiene también un sentido sagrado que se abre a las manifestaciones de la hibridación cultural. Se mezclan entonces la cosmogonía arcaica, construida con base en la lógica del maíz y el consumo que se asocia a los rituales católicos o cristianos. En la novela, por ejemplo, se describe ampliamente el consumo alimenticio que se hace en el marco de las fiestas, tales como la famosa celebración de Santa Cruz de las Cruces.

En cuanto a lo cosmogónico sigue siendo un tema de interés la concepción cíclica de la vida. Lo culinario es parte de esta, pues todo aquí está conectado. Cualquier tipo de comida en este sistema es semiosis de una cadena de implicaciones. Igualmente esta afirmación es válida para el proceso de la cocina, tal y como se puede apreciar en este encadenamiento: "Candelaria Reinosa, inmovilizada, clavados los ojos en el corazón de una hornilla llena de leños, brasas, llamas, humo. El humo a la llama, la llama a la brasa, la brasa al leño, el leño al árbol, el árbol a la tierra, la tierra al sueño" (Asturias, 1992, p. 225). El humo es en este ejemplo el signo que activa un complejo proceso semiótico. La cadena de conexiones sigue un camino lógico que finalmente conecta con el ser humano, pero el proceso continúa y a la vez el ser humano conecta de manera cíclica con el principio.

De acuerdo con Homi Bhabha, para el proceso de reconstrucción del discurso de la diferencia cultural no basta un mero cambio de contenidos y símbolos culturales. "Se requiere una revisión radical de la temporalidad social en la que puedan escribirse las 
historias emergentes, la rearticulación del "signo" en el cual las identidades culturales puedan inscribirse" (Bhabha, 2010, p. 212). Para entender semióticamente esta olla de pulique que nos presenta Miguel Ángel Asturias, hay que comprender el proceso de las contribuciones al sistema. Aunque persisten la cosmogonía cíclica, la dualidad hombre-maíz y el sentido de la muerte como alimento de la tierra, los arquetipos fundacionales han entrado en crisis. Nuevos condimentos, sabores y sustancias han modificado el plato que se sirve en la mesa actual. Son muy evidentes los procesos de hibridación cultural que se empiezan a manifestar en el seno de la comunidad. Los códigos culinarios son signos de resistencia, pues mantienen una importante reserva de productos y maneras de elaboración tradicional, pero igualmente muestran claras fisuras culturales o lo que Néstor García Caclini llamaba los dislocamientos, gracias a la incorporación de elementos y nuevos modos de preparar los platos. En resumen, el hombre que originalmente era de maíz, en el marco del enfrentamiento con los otros, reaparece con injertos de otras plantas.

\section{Bibliografía}

Asturias, M.Á. (1970 [1930]). Leyendas de Guatemala. Barcelona: Salvat.

Asturias, M.Á. (1992). Hombres de maíz. [Edición crítica G. Martin]. Madrid: Archivos CSIC.

Balzer, C. (2001). Las huellas del Popol Vuh en dos obras de Miguel Ángel Asturias. Revista literaria Alba de América. 20 (37 y 38), 245-257.

Barthes, R. (1971). Elementos de Semiología. (A. Méndez, tr.). Madrid: Talleres gráficos Montaña.

Bhabha, H. (2010). Nación y narración entre La ilusión de una Identidad y Las diferencias culturales. Buenos Aires: Editorial siglo XXI.

Carpentier, A. (2004). América, la imagen de una conjunción. Barcelona: Anthropos Editorial.

García-Canclini, N. (1990). Culturas híbridas. Estrategias para entrar y salir de la modernidad. México: Grijalbo, Consejo Nacional para la Cultura y las Artes.

Geertz, C. (1992). La interpretación de las culturas. Barcelona: Gedisa.

Kristeva, J. (1974). El texto de la novela. (J. Llovet, tr.). Barcelona: Lumen.

Lévi-Strauss, C. (1968). Mitológicas I. Lo crudo y lo cocido. México: F.C.E.

Lévi-Strauss, C. (1995). Tristes tropiques. Le grand livre de l'ethonogie contemporaine. Paris: Brobard \& Tupin.

López-García. J. (2003). Símbolos de la comida indígena guatemalteca: una etnografía de la culinaria Maya-Ch'orti'. Quito: Ediciones Abya-Yala.

Lotman, Y. (1979). Semiótica de la Cultura. Madrid: Cátedra.

Martí, J. (1979). "Nuestra América". En: Colección Pensamiento de Nuestra América. Tres documentos de Nuestra América. La Habana: Casa de las Américas.

Sandoval de Fonseca. (1975). Hombres de Maíz, trascendentalización de la existencia. Revista de Filología y Lingüística. (1), 1, 3-6. 